\title{
Long-term effect of lifestyle intervention on adiposity, metabolic parameters, inflammation and physical fitness in obese children: a randomized controlled trial
}

\author{
RC Vos ${ }^{1}, \mathrm{JM} \mathrm{Wit}^{2}, \mathrm{H} \mathrm{Pijl}^{3}$ and ECAM Houdijk ${ }^{1}$ \\ ${ }^{1}$ Department of Pediatrics, Juliana Children's Hospital/Haga Hospital, The Hague, The Netherlands; ${ }^{2}$ Department of \\ Pediatrics, Leiden University Medical Center, Leiden, The Netherlands and ${ }^{3}$ Department of Endocrinology and Metabolism, \\ Leiden University Medical Center, Leiden, The Netherlands
}

\begin{abstract}
Background: Behavioral lifestyle intervention, combined with parental involvement, is preferred over standard care or self-help in childhood obesity. The short-term results of such interventions are promising, but long-term follow-up results are equivocal. Objective: The objective of the present study was the short ( 3 months) and long-term ( 1 and 2 years follow-up) effect evaluation of a family-based multidisciplinary cognitive behavioral lifestyle intervention on markers of adiposity, metabolism, inflammation and physical fitness compared with standard care in children with obesity. Also the association between these outcome variables was determined.
\end{abstract}

Methods: In this prospective longitudinal clinical trial, obese children were randomly assigned to a 3-month family-based cognitive behavioral multidisciplinary lifestyle treatment $(n=40$; body mass index-standard deviation score (BMI-SDS) $4.2 \pm 0.7$; age; $13.3 \pm 2.0$ years) or to a control group receiving an initial advice on physical activity and nutrition ( $n=39$; BMI-SDS $4.3 \pm 0.6$; age $13.1 \pm 1.9$ years). Anthropometric data, physical fitness, metabolic parameters and inflammatory state were evaluated at baseline, after intervention (at 3 months) and at 1-year follow-up. At 2-year follow-up, anthropometric data and physical fitness were measured in the intervention group.

Results: An intervention effect after 1 year was found for adiposity ( $P=0.02$ for BMI-SDS, $P=0.03$ for waist circumference (WC)-SDS), physical fitness (absolute measured peak value of oxygen uptake $\left(\mathrm{ml} \mathrm{min}^{-1}\right)$, standardized for age and gender $\left(V O_{2 \text { peak }}\right.$-SDS), $\left.P<0.01\right)$ and insulin resistance $($ HOMA-SDS, $P=0.04)$. No significant intervention effect was found for serum lipid profile, high-sensitive C-reactive protein or for adiponectin. At 2-year follow-up, BMI-SDS in the intervention group $(n=31)$ was $3.8 \pm 1.2$ SDS, significantly less than at baseline $(P=0.02)$.

Conclusion: A positive 1-year follow-up treatment effect was found for adiposity, physical fitness and glucose homeostasis, but not for inflammatory markers. There was a significant long-term treatment effect on adiposity, although almost all children remained obese.

Nutrition and Diabetes (2011) 1, e9; doi:10.1038/nutd.2011.5; published online 3 October 2011

Keywords: obesity; children; physical fitness; inflammation; insulin resistance

\section{Introduction}

The rapidly increasing prevalence of childhood obesity observed during the last few decades is assumed to be mostly the result of changes in environmental factors such as urbanization, economic growth, technical changes and culture. These changes have resulted in a large shift, both in diet and physical activity patterns. The modern 'Western diet' is high in saturated fats, sugar and refined foods, but

Correspondence: Dr RC Vos, Department of Pediatrics, Juliana Children's Hospital/Haga Hospital, Sportlaan 600, The Hague 2566 MJ, The Netherlands. E-mail: r.vos@hagaziekenhuis.nl

Received 20 January 2011; accepted 28 February 2011 low in fiber. Simultaneously a physically active lifestyle has changed to a more sedentary one. ${ }^{1}$

Obesity in childhood tends to persist into adulthood, ${ }^{2-4}$ and adult obesity is associated with a higher risk for developing type 2 diabetes mellitus and cardiovascular disease. ${ }^{2,4}$ Moreover, it has become clear that the adipose tissue is not only just a fat depot but also an endocrine organ, producing hormones and inflammation-related factors that contribute to the chronic state of inflammation observed in obesity. ${ }^{5,6}$ Increased levels of the proinflammatory cytokines such as high-sensitive C-reactive protein $(\mathrm{hsCRP})^{7-9}$ and decreased levels of adiponectin have been found in children with obesity and insulin resistance. ${ }^{10,11}$ 
An appropriate approach to reduce the obesity-related health risks is weight loss. Current treatment recommendations for childhood obesity are lifestyle interventions, including nutritional and physical activity modification guided by social cognitive behavioral techniques. ${ }^{12-14}$ One of the central assumptions of a cognitive behavioral approach is that higher levels of self-confidence increase the likelihood of lifestyle change. ${ }^{15}$ In addition, the lifestyle treatment approach has been shown to be equally successful in both clinical-, community- and school-based settings. ${ }^{13,14,16}$ Moreover, the results of a recent metaanalysis on lifestyle interventions for obese youth showed that lifestyle interventions lasting for only a few months can be expected to produce significant changes in body weight. ${ }^{13}$ Also involvement of parent in the treatment of obese children showed a clearly beneficial effect on treatment results. ${ }^{13,14}$ A better treatment result is found when parents are educated about healthy nutrition and when training in behavioral modification was provided. ${ }^{13}$ Better treatment outcomes have also been observed after group therapy compared with individual treatment only, probably because of the positive effect of peer support. ${ }^{17}$ Furthermore, the intensity of the program, defined as more contact time with professional support during the intervention rather than the total duration of the intervention, appears important for its efficacy. ${ }^{18}$ The results of behavioral lifestyle interventions on adiposity, metabolism, inflammation and physical fitness immediately after treatment are promising. ${ }^{8-10,16,19-23}$ However, the long-term follow-up effects of such interventions on obesity and associated comorbidity are uncertain. ${ }^{18,24}$ A younger age at start and a substantial decrease of BMISDS (body mass index was expressed as standard deviation score) during the intervention have been reported to predict a long-term favorable effect, ${ }^{25}$ but more research is needed to delineate the long-term effects of behavioral lifestyle interventions.

In this paper, we report on the short (3 months) and longterm ( 1 and 2 years) effect of a family-based multidisciplinary lifestyle intervention on markers of adiposity, physical fitness, metabolic parameters and inflammation compared with standard care in obese children.

\section{Materials and methods}

Study design and setting

We performed a longitudinal prospective randomized clinical trial to evaluate the effects of a family-based multidisciplinary lifestyle intervention on various clinical and physiological features of obese children (as defined by Cole et $a .^{26}$ ) aged 8-17 years, who were referred to a pediatric clinic (Juliana Children's Hospital, the Hague). Children who met the inclusion criteria were randomized to receive either a family-based multidisciplinary lifestyle intervention or standard care. Before randomization, stratification took place for age ( 8 to less than 12 years and 12 to less than 17 years), gender (male vs female) and ethnicity (North European vs others). Normative data for physical fitness, the inflammation parameters and glucose homeostasis were collected from a group of healthy children with a normal body weight recruited by the youth health services (Jeugd GGD Haaglanden). The study was conducted according to the 'Declaration of Helsinki' and approval was obtained from the Regional Medical Ethics Committee (Zuid-West Holland). All parents and children gave their written informed consent, after they had been given detailed written explanation regarding the aim of the study, discomfort and inconvenience associated with it and the option to withdraw at any time.

\section{Participants}

Potential participants were excluded if their knowledge of the Dutch language, intelligence or social skills were insufficient to participate in the trial. Other exclusion criteria were the use of medication that might have an effect on weight loss, medical comorbidity that could affect participation or previous enrollment in another cognitive behavioral treatment program with focus on reducing obesity. Inclusion criteria were simple obesity, subjects of 8-17 years of age and referral to a pediatrician. From the 108 obese children who met the inclusion criteria, 81 agreed to participate. Most given reasons of refusal were: (1) not wanting to take the risk to be randomized to the control group and consequently wait for a year before starting treatment; and (2) not wanting to invest into the requested time for treatment. Overall, 41 children were randomized to the intervention group and 40 to the control group (Figure 1). The normal-weight control group consisted of 34 healthy, age-, gender- and ethnicity-matched children with normal body weight for height.

\section{Family-based multidisciplinary lifestyle intervention}

The family-based multidisciplinary lifestyle intervention of the intervention group consisted of a screening phase of individual counseling of the children with their parents, followed by an intensive phase of group sessions during 3 months. The group treatment consisted of seven group meetings for the children, five separate parent meetings and one parent meeting together with the children. Meetings of duration of $2.5 \mathrm{~h}$ were held once every 2 weeks. The children meetings were held on weekday afternoons at the hospital. The five separate parent meetings were provided on weekdays after working hours. Subsequently, refresher follow-up sessions (2-3 sessions per year) were offered for a total period of 2 years (Table 1$)$.

The control group received standard care and advice, at start of the trial, on how to increase their physical activity, decrease their sedentary activities and improve their eating behavior according to the Dutch standards for healthy nutrition. After 1 year, all children in the control group 


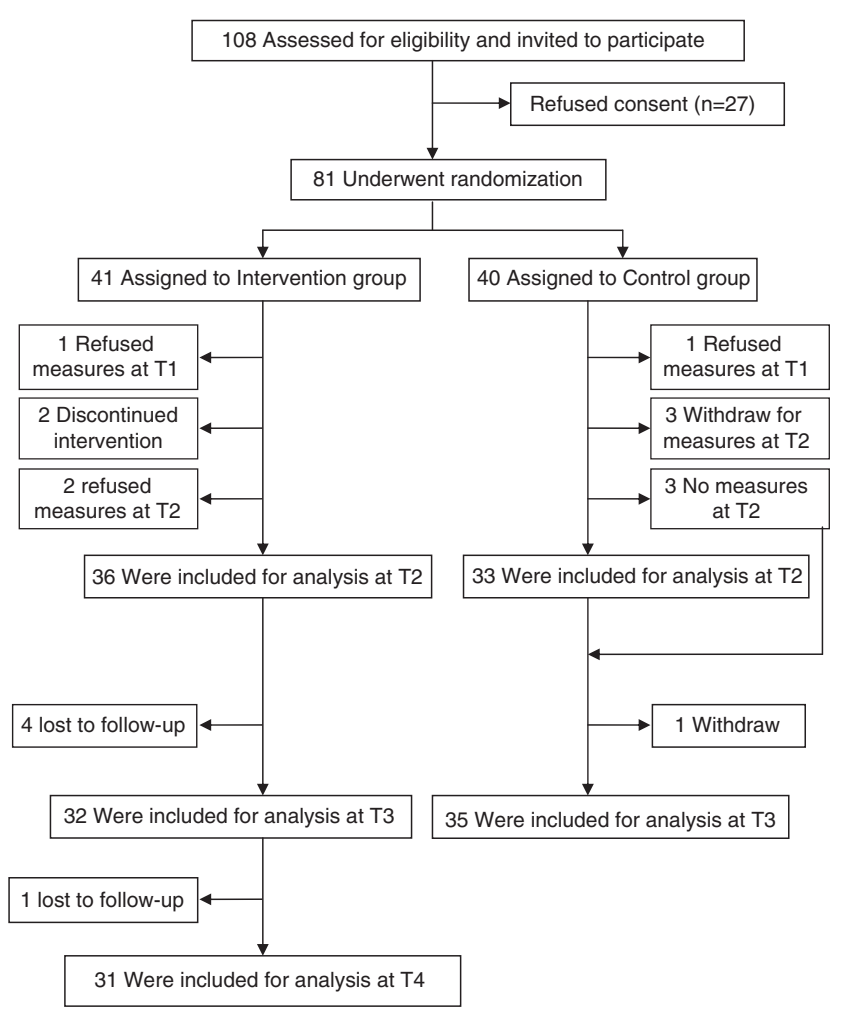

Figure 1 Flow of participants through study with primary outcome measurement (BMI-SDS).

were offered the opportunity to participate in the familybased multidisciplinary lifestyle intervention.

\section{Clinical measures}

Measurements were taken before (T1) and after the 3-month treatments in the intervention group (T2) and after a followup period of 12 months after start (T3). The intervention group was also evaluated after 24 months (T4). In the normal-weight control group, tests and blood samples were determined once.

Weight was measured to the nearest of $0.1 \mathrm{~kg}$ using an electronic scale (SECA 911, Vogel \& Halke, Hamburg, Germany) and height to the nearest of $0.1 \mathrm{~cm}$ with a stadiometer (Holtain Limited, Crymych, Dyfed, UK) in underwear and barefoot by an experienced assistant. The BMI was calculated as weight/height squared $\left(\mathrm{kg} \mathrm{m}^{-2}\right)$. Subjects were classified as obese using BMI gender- and age-specific international cutoff levels. ${ }^{26}$ BMI was expressed as standard deviation score (SDS) for Dutch references. ${ }^{27}$ The 1980 reference data for weight and height were used to obtain a realistic view on the degree of obesity without the data being biased by the increased prevalence rate of childhood obesity. Waist circumference (WC, in $\mathrm{cm}$ ) was measured with an anthropometric tape midway between the lower rib margin and the iliac crest at the end of gentle expiration and expressed as SDS (WC-SDS). ${ }^{28}$ The WC/height (both in $\mathrm{cm}$ ) ratio $(\mathrm{WC} / \mathrm{Ht}$ ) was used as an additional measure for increased health risk. Blood pressure was determined in a relaxed sitting position; measurement was carried out with an electronic device (Criton Dinamap, No. 8100, GE Healthcare, Hoevelaken, the Netherlands), in duplicate; the last measurement was used for further analysis.

Ethnicity was determined according to self-reports given by the parents. For this analysis, subjects were classified as 'Northern European' (38\% of the total sample) when both parents reported the Northern-European ethnicity, and 'others' (62\%) when one or both parents reported another ethnicity. Subjects in the 'others' group were mainly of Hindustani (28\% of total sample) and Mediterranean (28\% of total sample) origin.

Pubertal development was recorded by the pediatrician according to Tanner. ${ }^{29}$ Breast development in girls and genital development in boys was used for pubertal classification into two groups: prepubertal (breast or genital stage $\leqslant 1$ ) and pubertal (stages 2-5).

\section{Voluntary maximal exercise test}

The physical fitness of the children was determined by a voluntary maximum exercise test on a treadmill using breath-by-breath analysis and plots according to Wasserman. ${ }^{30}$

The exercise test consisted of three stages; a reference stage (2-min rest before the exercise test), the test stage (the exercise test until voluntary exhaustion occurred) and a recovery stage (2-min recovery measurement in rest after the exercise test). The test stage started with a velocity of $4 \mathrm{~km} \mathrm{~h}^{-1}$ and an angle of $0 \%$ during $1 \mathrm{~min}$. Every minute the velocity increased by $0.5 \mathrm{~km} \mathrm{~h}^{-1}$ and the angle by $2 \%$, until voluntary exhaustion occurred. During the test, all subjects were verbally encouraged to perform maximally. At the end of the test, the children were asked to grade the level of exhaustion using the Borg scale ${ }^{31}$ and explain their reason for ending the test.

Peak values were based on the heart rate and a respiratory exchange ratio of $>1.0$ between oxygen uptake $\left(\mathrm{VO}_{2}\right)$ and carbohydrate output. This level is, in children, equivalent with the anaerobic threshold at which point exhaustion starts. ${ }^{32}$ This latter criterion is a generally accepted approach to establish if peak values are reached. The physical fitness was determined from the absolute measured peak value of $\mathrm{VO}_{2}\left(\mathrm{ml} \mathrm{min}^{-1}\right)$, standardized for age and gender $\left(\mathrm{VO}_{2 \text { peak }}{ }^{-}\right.$ SDS). Also the peak $\mathrm{VO}_{2}$ adjusted for body weight was determined by dividing the absolute $\mathrm{VO}_{2}$ by body weight $\left(\mathrm{ml} \mathrm{min}{ }^{-1}\right.$ per $\mathrm{kg}$ ) and standardized it for age and gender $\left(\mathrm{VO}_{2 \text { peak }}-\mathrm{SDS}-\mathrm{kg}\right)$. In obese subjects, it is common to use this latter approach for physical fitness because the peak value of the absolute $\mathrm{VO}_{2}$ is biased, as obese subjects usually also have a large absolute amount of muscle weight compared with normal-weight peers. ${ }^{30}$ 
Table 1 Characteristics of the family-based multidisciplinary lifestyle intervention

\begin{tabular}{ll}
\hline Components & Description \\
\hline $\begin{array}{l}\text { Screening phase/ } \\
\text { individual counseling }\end{array}$ & $\begin{array}{l}\text { During the screening phase, children and their parents were interviewed at two separate occasions and all interviewed individually by the } \\
\text { multidisciplinary team consisting of a dietitian, a child physiotherapist, a child psychologist and a social worker. Throughout those two } \\
\text { separate meetings, an individual advice was given by the multidisciplinary team, based on the personal situation of each participating } \\
\text { family. }\end{array}$
\end{tabular}

Individual nutritional A 3-day dietary recall (1 weekend day included) was used by the dietitian to get more insight into the dietary habits of the children. advice Information was provided about nutrition and healthy eating behavior according to the traffic-light nutrition list. ${ }^{40}$ The traffic-light nutrition list identifies several main food groups (fruits, vegetables, grains, milk and other dairy products, meat, fish and others). Foods within each group were color-coded so as to reflect the caloric density per average serving and the Dutch standards for healthy nutrition. The colors are green for 'go', orange for 'approach with caution' and red for 'stop'. The children and parents were involved in planning their own daily diet for themselves according to the traffic-light nutritional list.

Individual physical activity counseling

Individual psychological counseling Children's group meetings

Parent group meetings

Follow-up meetings
To obtain insight into the child's general physical activity behavior during the week, a physical activity questionnaire was filled out by a child physiotherapist. Children were asked how they traveled to school (by foot, by bicycle, by public transportation or by car); physical fitness classes at school, spare-time sport activities and daily computer and TV use, as well as the duration spend at all these activities were noted. The information from this questionnaire was used for advice on how to increase and optimize physical activity during everyday life, such as walking to nearby destinations and reducing sedentary activities (use of computer and TV).

By means of motivational interviewing, the child psychologist helped the children to adapting to a new lifestyle in order to reduce body weight. Before the child started with the group sessions, individual treatment goals (reduction of $10 \%$ of body weight during 3 months group sessions) were written down in a contract to avoid disappointment.

Most children with obesity have negative experiences with group activities. For example, they are often not included in social events or chosen last by sport activities. Therefore, during the first session, much time is spent in getting acquainted with each other. A good group bond is important for the effect of the treatment because peer support can be very helpful in the treatment of obese children. The main educational focus of the first two meetings is on nutritional information of a healthy eating pattern and the balance between energy intake and energy expenditure. During the subsequent meetings, emphasis was put in self-control techniques to cope with difficult situations (e.g., birthday parties, holidays, lunch breaks at school, being at home alone). Problem solving alternatives are debated (e.g., to avoid a situation, doing something else, participate in a situation and eat less or participate followed by extra exercise afterward). Other psychoeducational topics reviewed were self-reward (when coping well with a difficult situation) and self-regulation situations (making a plan how to integrate healthy behavior in daily living). Stimulus control was also one of the psycho-educational topics (remove unhealthy stimuli at home, encourage healthy behavior, eat at the dinner table, reduction of environmental stimuli linked to eating). Topics of the last two meetings were self-image (focus on positive things about themselves) and coping strategies on dealing with teasing.

Topics discussed during the parent meetings included the necessity to change their own lifestyle as well, information on healthy nutrition (product information, quantities, eating moments, eating locations) and how to help their children. Parents received advice on parenting styles (boundaries setting with regard to eating behavior, giving positive feedback). During the last meeting, a therapist discusses the role of all other family members with regard to the treatment in the family (e.g., are other family members supportive, how do they cope with the lifestyle changes).

In order to maintain the newly learned behavior refresh follow-up meetings were given during the first 2 years (2-3 meetings per year). The child psychologist and the social worker organize these follow-up meetings. The topics repeated were: problem-solving techniques and relapse-prevention techniques.

\section{Biochemical measures}

With the subject in supine position, blood samples were taken by venipuncture after an overnight fast. Before blood sampling, the fasting state was verbally confirmed by the participant and the parent(s). After blood sampling, serum samples of insulin, adiponectin and hsCRP were stored at $-80^{\circ} \mathrm{C}$ before analysis. All blood samples were analyzed in accredited clinical chemical and hematology laboratories (Haga Hospital, the Hague and Leiden University Medical Center, Leiden, The Netherlands).

Glucose was analyzed from lithium heparin plasma by the glucose oxidase method with the Unicel DxC 800 (Beckman Coulter, Woerden, the Netherlands). Plasma insulin was analyzed by a radioimmunoassay method (DSL-1600, Beckman Coulter; intra-assay coefficient of variation 4.5-8.3\%; inter-assay coefficient of variation $4.7-12.2 \%$; sensitivity $1.3 \mu \mathrm{Uml}^{-1}$ ). An index for insulin resistance was calculated according to the Homeostasis Model Assessment for insulin resistance (HOMA-IR) formula: (fasting insulin $\left(\mu \mathrm{Uml}^{-1}\right) \times$ fasting glucose $\left.\left(\mathrm{mmoll}^{-1}\right)\right) / 22.5{ }^{33}$ Standard deviation scores for HOMA-IR (HOMA-SDS) were calculated, based on gender- and age-specific reference values. ${ }^{34}$

High-density lipoprotein (HDL) cholesterol level was analyzed by homogenic enzymatic colorimetry and triglyceride (TG) level by automatized colorimetry, both determined by bynchon Lx20 Pro/unicel DXC 800 (Beckman Coulter, Brea, CA, USA).

High-sensitive CRP was analyzed by immunoturbidimetric assay with Cobas Integra 800 (Roche Diagnostics, Indianapolis, IN, USA; measuring range $0.15-20.0 \mathrm{mgl}^{-1}$; sensitivity $0.3 \mathrm{mg} \mathrm{l}^{-1}$ with an inter-assay coefficient of variation $<10 \%$ ). Adiponectin level was assayed by human adiponectin 
radioimmunoassay (adiponectin kit hadp-61hk, Millipore, Billerica, MA, USA; intra-assay coefficient of variation 1.78-6.21\%; inter-assay coefficient of variation $6.9-9.25 \%$; sensitivity; $0.78 \mathrm{ng} \mathrm{ml}^{-1}$ ).

\section{Statistical analysis}

The analysis was performed using the Statistical Package for Social Science version 17.0 for Windows (SPSS Inc., Chicago, IL, USA) and the level of significance was set at $P<0.05$. Data were checked for normality before analysis, using descriptive statistics for skewness, kurtosis and Shapiro-Wilk test. Fasting insulin was transformed to the natural logarithm. Data were expressed as mean \pm standard deviation (continuous variables) and as count and percentage (categorical variables), unless defined otherwise. One-way analysis of variance, with Bonferroni correction for multiple testing, was used to compare the intervention group, obese control group and normal-weight control group at baseline. Analysis of variance for repeated measures were used to determine the mean study parameters over time per group (intervention and obese control group). The mixed model for repeated measures was used to determine the effect of intervention (mean difference between change in the intervention and control group) over time for all the parameters separately, adjusted for baseline values. Pearson correlation analysis was used to assess the associations between the study parameters at baseline.

\section{Results}

Clinical baseline data of 79 obese children $(n=40$ in the intervention group and $n=39$ controls) and of 34 normalweight children are shown in Table 2 . The ratio prepubertal (Tanner $\leqslant 1$ ) vs pubertal (Tanner $2-5$ ) children was not significantly different between groups $(P=0.11)$. At baseline, the intervention and obese control group did not significantly differ in measures of adiposity (BMI-SDS, WC-SDS, $\mathrm{WC} / \mathrm{Ht})$, physical fitness $\left(\mathrm{VO}_{2 \text { peak }}-\mathrm{SDS}, \mathrm{VO}_{2 \text { peak }}-\mathrm{SDS}-\mathrm{kg}\right)$, metabolic parameters (insulin, glucose, HOMA-SDS, HDL, TG, blood pressure) and inflammation (adiponectin, hsCRP). At baseline, the parents of both intervention and obese control group were on average obese as well, showing no significant difference between groups; BMI of the father $\left(30.0 \pm 7.1\right.$ vs $28.4 \pm 4.4 \mathrm{~kg} \mathrm{~m}^{-2}$, respectively) and BMI of the mother $\left(31.0 \pm 9.0\right.$ vs $\left.31.2 \pm 6.2 \mathrm{~kg} \mathrm{~m}^{-2}\right)$.

Obese subjects in both the intervention and control groups showed a significantly $(P<0.01)$ lower physical fitness $\left(\mathrm{VO}_{2 \text { peak }}-\mathrm{SDS}, \mathrm{VO}_{\text {2peak }}-\mathrm{SDS}-\mathrm{kg}\right.$ ) and $\mathrm{HDL}$ compared with the normal-weight control group and a higher systolic blood pressure $(P=0.02$ and $P=0.06$, respectively). Significantly higher fasting insulin $(P=0.03)$, HOMA-SDS $(P=0.05)$ and TG $(P=0.01)$ were found in the obese intervention group compared with the normal-weight control group.
Table 2 Baseline subject characteristics

\begin{tabular}{|c|c|c|c|}
\hline & $\begin{array}{l}\text { Intervention } \\
\text { group } \\
(\mathrm{n}=40)\end{array}$ & $\begin{array}{l}\text { Control } \\
\text { group } \\
(\mathrm{n}=39)\end{array}$ & $\begin{array}{l}\text { Normal-weight } \\
\text { control group } \\
\quad(\mathrm{n}=34)\end{array}$ \\
\hline Gender (M/F) & $18 / 22$ & $19 / 20$ & $14 / 20$ \\
\hline Ethnicity (North European/other) & $14 / 26$ & $11 / 28$ & $18 / 16$ \\
\hline Puberty (Tanner $\leqslant 1 / 2-5)$ & $5 / 35$ & $8 / 31$ & $7 / 27$ \\
\hline Age (year) & $13.3 \pm 2.0$ & $13.1 \pm 1.9$ & $13.2 \pm 2.4$ \\
\hline Weight (kg) & $85.7 \pm 18.4^{*}$ & $85.7 \pm 18.6^{*}$ & $51.7 \pm 15.1$ \\
\hline Height (cm) & $161.9 \pm 9.7$ & $161.4 \pm 11.0$ & $160.2 \pm 14.1$ \\
\hline $\mathrm{BMI}\left(\mathrm{kg} \mathrm{m}^{-2}\right)$ & $32.4 \pm 4.7^{*}$ & $32.5 \pm 3.9^{*}$ & $19.7 \pm 3.3$ \\
\hline BMI-SDS & $4.2 \pm 0.7^{*}$ & $4.3 \pm 0.6^{*}$ & $0.5 \pm 1.4$ \\
\hline WC $(\mathrm{cm})$ & $91.1 \pm 9.1^{*}$ & $90.5 \pm 7.7^{*}$ & $67.0 \pm 8.7$ \\
\hline WC-SDS & $3.7 \pm 1.0^{*}$ & $3.7 \pm 0.9^{*}$ & $0.3 \pm 0.9$ \\
\hline $\mathrm{WC} / \mathrm{Ht}$ & $0.56 \pm 0.04^{*}$ & $0.56 \pm 0.04^{*}$ & $0.42 \pm 0.04$ \\
\hline $\mathrm{VO}_{2 \text { peak }}-\mathrm{SDS}$ & $1.7 \pm 1.5^{*}$ & $2.2 \pm 1.5^{*}$ & $0.0 \pm 1.4$ \\
\hline $\mathrm{VO}_{2 \text { peak }}-\mathrm{SDS}-\mathrm{kg}$ & $-3.0 \pm 1.0^{*}$ & $-2.8 \pm 1.0^{*}$ & $-0.8 \pm 1.1$ \\
\hline Glucose $\left(\mathrm{mmoll}^{-1}\right)$ & $5.3 \pm 0.4$ & $5.2 \pm 0.4$ & $5.2 \pm 0.5$ \\
\hline Insulin $\left(\mathrm{mUI}^{-1}\right)$ & $19.5 \pm 12.2^{*}$ & $14.9 \pm 8.0$ & $13.5 \pm 9.1$ \\
\hline HOMA-IR & $4.6 \pm 2.9$ & $3.4 \pm 1.9$ & $3.2 \pm 2.3$ \\
\hline HOMA-SDS & $2.1 \pm 2.3^{*}$ & $1.2 \pm 1.3$ & $1.0 \pm 2.1$ \\
\hline $\mathrm{HDL}\left(\mathrm{mmol} \mathrm{I}^{-1}\right)$ & $1.1 \pm 0.3^{*}$ & $1.1 \pm 0.2^{*}$ & $1.3 \pm 0.2$ \\
\hline Triglycerides $\left(\mathrm{mmoll}^{-1}\right)$ & $1.2 \pm 1.0^{*}$ & $0.9 \pm 0.5$ & $0.7 \pm 0.3$ \\
\hline Systolic blood pressure $(\mathrm{mm} \mathrm{Hg})$ & $125 \pm 13^{*}$ & $126 \pm 12^{*}$ & $119 \pm 9$ \\
\hline Diastolic blood pressure $(\mathrm{mm} \mathrm{Hg})$ & $65 \pm 9$ & $65 \pm 7$ & $67 \pm 9$ \\
\hline Adiponectin $\left(\mathrm{ng} \mathrm{ml}^{-1}\right)$ & $8.6 \pm 3.8$ & $8.5 \pm 3.3$ & $9.7 \pm 4.0$ \\
\hline $\operatorname{hsCRP}\left(\mathrm{mgl}^{-1}\right)$ & $2.3 \pm 2.1$ & $1.8 \pm 1.5$ & $0.6 \pm 0.9$ \\
\hline
\end{tabular}

Abbreviations: BMI, body mass index; BMI-SDS, BMI-standard deviation score; F, female; HDL, high-density lipoprotein; HOMA-IR, Homeostasis Model Assessment for insulin resistance; HOMA-SDS, standard deviation scores for HOMA-IR; hsCRP, high-sensitive C-reactive protein; $M$, male; $V_{2} O_{2 \text { peak }}-S D S-k g$, absolute oxygen uptake by body weight $\left(\mathrm{ml} \mathrm{min}^{-1}\right.$ per $\mathrm{kg}$ ) and standardized it for age and gender; $\mathrm{VO}_{2 \text { peak }}$-SDS, absolute measured peak value of oxygen uptake $\left(\mathrm{ml} \mathrm{min}^{-1}\right)$, standardized for age and gender; WC, waist circumference; WC/Ht; WC and height ratio; WC-SDS, WC expressed as standard deviation score. *Significantly different compared with normal weight control group, $P<0.05$, tested using ANOVA for comparing between groups. Results are expressed as mean \pm s.d.

During the 3 months intensive phase of the treatment, five boys and five girls missed two meetings, two boys and five girls missed one meeting and the remaining children attended all the group meetings. The short-term (T2 at 3 months) and long-term (T3 after 1-year follow-up) results are shown in Table 3 . On both these study occasions, measures of adiposity were significantly reduced in the intervention group, with 10\% decreased BMI-SDS and 19\% decreased WC-SDS after 1-year follow-up compared with baseline. The corresponding values in the obese control group remained unchanged compared with baseline. After 1-year follow-up, the $\mathrm{VO}_{2 \text { peak }}$-SDS-kg in the intervention group had increased by $20 \%$, whereas a reduction of $18 \%$ was observed in the obese control group (Figure 2). Borg scores for subjective-experienced exhaustion did not significantly change over time within and between the groups. Measures for fasting insulin and HOMA-SDS were equal to baseline values in the intervention group at all study occasions. In the control group, these measures slightly increased compared with baseline. Blood pressure decreased more in the intervention group vs baseline values compared with the obese control group. Lipid profile and inflammatory state in both the groups remained unchanged. 
Table 3 Outcome parameters at start (T1), after 3 months (T2) and after 12 months (T3) in the intervention and control groups

\begin{tabular}{|c|c|c|c|c|c|c|}
\hline & \multicolumn{3}{|c|}{ Intervention group } & \multicolumn{3}{|c|}{ Control group } \\
\hline & $T 1(\mathrm{n}=40)$ & $T 2(\mathrm{n}=36)$ & $T 3(\mathrm{n}=32)$ & $T 1(\mathrm{n}=39)$ & $T 2(\mathrm{n}=33)$ & $T 3(\mathrm{n}=35)$ \\
\hline BMI-SDS & $4.2(4.0 ; 4.4)$ & $4.0(3.7 ; 4.3)$ & $3.8(3.4 ; 4.2)$ & $4.3(4.1 ; 4.5)$ & $4.2(4.0 ; 4.5)$ & $4.2(4.0 ; 4.5)$ \\
\hline WC-SDS & $3.7(3.3 ; 4.0)$ & $3.4(2.9 ; 3.8)$ & $3.0(2.5 ; 3.6)$ & $3.7(3.4 ; 4.0)$ & $3.7(3.3 ; 4.1)$ & $3.5(3.1 ; 4.0)$ \\
\hline $\mathrm{WC} / \mathrm{Ht}$ & $0.56(0.55 ; 0.58)$ & $0.55(0.53 ; 0.57)$ & $0.53(0.51 ; 0.56)$ & $0.56(0.55 ; 0.57)$ & $0.56(0.55 ; 0.58)$ & $0.56(0.54 ; 0.57)$ \\
\hline $\mathrm{VO}_{2 \text { peak }}$-SDS & $1.7(1.2 ; 2.2)$ & $1.7(1.2 ; 2.2)$ & $1.7(1.1 ; 2.3)$ & $2.2(1.7 ; 2.7)$ & $1.7(1.2 ; 2.2)$ & $1.1(0.6 ; 1.6)$ \\
\hline $\mathrm{VO}_{2 \text { peak }}$-SDS-kg & $-3.0(-3.3 ;-2.6)$ & $-2.7(-3.1 ;-2.3)$ & $-2.4(-3.0 ;-1.9)$ & $-2.8(-3.2 ;-2.5)$ & $-2.9(-3.3 ;-2.5)$ & $-3.3(-3.7 ;-2.9)$ \\
\hline Glucose $\left(\mathrm{mmoll}^{-1}\right)$ & $5.3(5.1 ; 5.4)$ & $5.3(5.1 ; 5.4)$ & $5.1(5.0 ; 5.2)$ & $5.2(5.1 ; 5.3)$ & $5.3(5.0 ; 5.6)$ & $5.1(5.0 ; 5.3)$ \\
\hline Insulin $\left(\mathrm{mUl}^{-1}\right)$ & $19.5(15.6 ; 23.4)$ & $17.4(13.1 ; 21.7)$ & $20.5(15.2 ; 25.9)$ & $14.9(12.3 ; 17.5)$ & $20.3(15.5 ; 25.0)$ & $18.8(15.6 ; 21.9)$ \\
\hline HOMA-SDS & $2.1(1.4 ; 2.9)$ & $1.7(0.8 ; 2.5)$ & $2.2(1.1 ; 3.3)$ & $1.2(0.7 ; 1.6)$ & $2.2(1.1 ; 3.4)$ & $1.7(1.2 ; 2.3)$ \\
\hline $\mathrm{HDL}\left(\mathrm{mmoll}^{-1}\right)$ & $1.1(1.1 ; 1.2)$ & $1.1(1.0 ; 1.2)$ & $1.1(1.0 ; 1.2)$ & $1.1(1.1 ; 1.2$ & $1.2(1.0 ; 1.3)$ & $1.1(1.0 ; 1.2)$ \\
\hline $\mathrm{TG}\left(\mathrm{mmoll}^{-1}\right)$ & $1.2(0.8 ; 1.5)$ & $1.2(0.9 ; 1.5)$ & $1.1(0.8 ; 1.4)$ & $0.9(0.8 ; 1.1)$ & $1.0(0.9 ; 1.2)$ & $1.0(0.8 ; 1.3)$ \\
\hline $\mathrm{SBP}(\mathrm{mm} \mathrm{Hg})$ & $125(121 ; 129)$ & $123(119 ; 127)$ & $118(114 ; 122)$ & $126(123 ; 131)$ & $125(121 ; 129)$ & $122(177 ; 128)$ \\
\hline DBP $(\mathrm{mm} \mathrm{Hg})$ & $65(62 ; 67)$ & $59(56 ; 62)$ & $57(54 ; 61)$ & $65(62 ; 67)$ & $62(58 ; 66)$ & $59(56 ; 62)$ \\
\hline Adiponectin $\left(\mathrm{ng} \mathrm{ml}^{-1}\right)$ & $8.6(7.4 ; 9.8)$ & $9.2(7.5 ; 10.9)$ & $9.4(7.4 ; 11.4)$ & $8.5(7.4 ; 9.6)$ & $9.1(7.8 ; 10.5)$ & $8.9(7.3 ; 10.5)$ \\
\hline $\operatorname{hsCRP}\left(\mathrm{mgl}^{-1}\right)$ & $2.3(1.6 ; 3.0)$ & $1.9(1.2 ; 2.6)$ & $1.9(1.1 ; 2.8)$ & $1.8(1.3 ; 2.3)$ & $2.5(1.4 ; 3.7)$ & $2.1(1.5 ; 2.8)$ \\
\hline
\end{tabular}

Abbreviations: BMI-SDS, body mass index-standard deviation score; DBP, diastolic blood pressure; HDL, high-density lipoprotein; HOMA-SDS, standard deviation scores for Homeostasis Model Assessment for insulin resistance; SBP, systolic blood pressure; TG, triglyceride; $\mathrm{VO}_{2 \text { peak }}-\mathrm{SDS}$-kg, absolute oxygen uptake by body weight $\left(\mathrm{ml} \mathrm{min}^{-1}\right.$ per $\mathrm{kg}$ ) and standardized it for age and gender; $\mathrm{VO}_{2 \text { peak }}-\mathrm{SDS}$, absolute measured peak value of oxygen uptake ( $\left.\mathrm{ml} \mathrm{min}^{-1}\right)$, standardized for age and gender; WC/Ht; waist circumference and height ratio; WC-SDS, WC expressed as standard deviation score. Results are expressed as mean (95\% confidence interval).

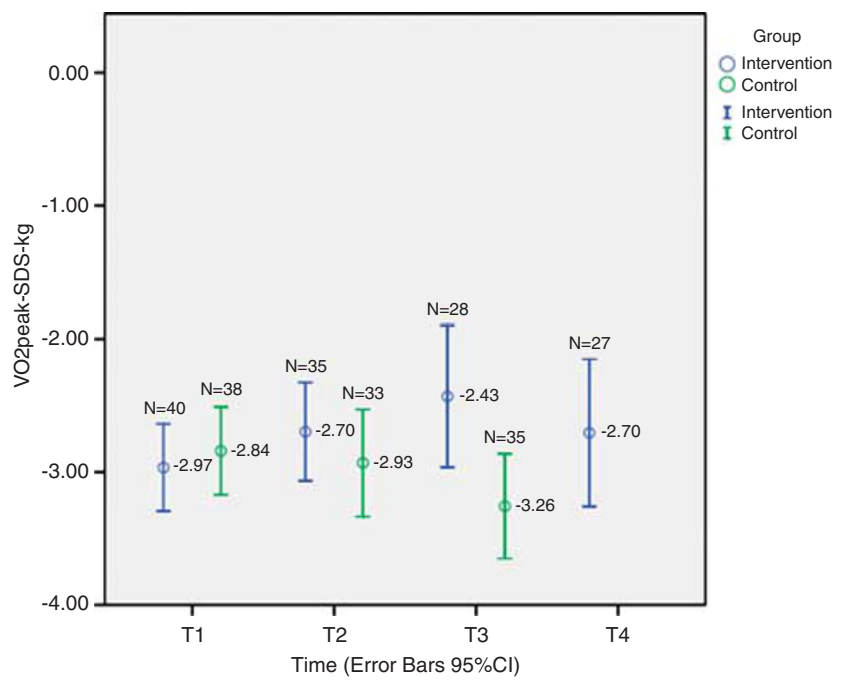

Figure 2 Physical fitness over time in the intervention and control group.

The effect of the intervention on the outcome parameters after 1-year follow-up is shown in Table 4 as well. In order to adjust for differences in baseline values between groups, the baseline values were put in the model as covariates. The mean differences between the intervention and obese control group, adjusted for baseline differences, were statistically significant for all the parameters of adiposity (BMI-SDS, WC-SDS, WC/Ht), physical fitness $\left(\mathrm{VO}_{2 \text { peak }}-\mathrm{SDS}\right.$, $\mathrm{VO}_{2 \text { peak }}-\mathrm{SDS}-\mathrm{kg}$ ) and for HOMA-SDS.

At 2-year follow-up, data on adiposity and physical fitness were available in 31 children in the intervention group. Measures for adiposity were similar to T3 (3.8 \pm 1.2 BMI-SDS and $3.2 \pm 1.8$ WC-SDS). BMI-SDS was still significantly lower than at baseline in these 31 children (4.2 \pm 0.7 SDS, $P=0.02)$, but only three children reached a BMI $<+2$ SDS. The physical fitness adjusted for body weight was still 10\% better compared with baseline, but had returned to the T2 value $\left(-2.7 \pm 1.4 \mathrm{ml} \mathrm{min}^{-1}\right.$ per $\left.\mathrm{kg}\right)$.

Pearson correlation analyses between the study parameters at baseline are shown in Table 5. A strongly significant inverse correlation was found between adiposity (BMI-SDS, WC-SDS, WC/Ht) and $\mathrm{VO}_{2 \text { peak }}$-SDS-kg. A less pronounced positive relation was found for all markers for adiposity with metabolic parameters (fasting insulin, HOMA-SDS, TG, systolic blood pressure) and hsCRP and an inverse relationship with HDL and adiponectin. Physical fitness, adjusted for body weight, correlated inversely with metabolic parameters (fasting insulin, fasting glucose, HOMA-SDS, TG, systolic blood pressure) and with hsCRP, and correlated positively with HDL and adiponectin. An inverse correlation was found between adiponectin and HOMA-SDS and systolic blood pressure. A positive correlation was found between adiponectin and HDL.

\section{Discussion}

Our family-based multidisciplinary lifestyle intervention showed a positive effect on all the parameters of adiposity and physical fitness, directly after the intervention and at follow-up after 1 and 2 years. We also found a modest but significant intervention effect on insulin resistance (expressed as HOMA-SDS), that is, unchanged values over time in the intervention group compared with increasing values of HOMA-SDS, with persisting adiposity in the obese 
Table 4 Effect of intervention on markers of adiposity, physical fitness, metabolic parameters and inflammation

\begin{tabular}{|c|c|c|c|c|c|c|}
\hline \multirow[t]{2}{*}{ Parameters } & \multicolumn{2}{|c|}{ Intervention group } & \multicolumn{2}{|c|}{ Obese control group } & \multicolumn{2}{|c|}{ Difference between two obese groups } \\
\hline & $\begin{array}{l}\text { Change during } \\
\text { first } 12 \text { months }\end{array}$ & $95 \% \mathrm{Cl}$ & $\begin{array}{l}\text { Change during } \\
\text { first } 12 \text { months }\end{array}$ & $95 \% \mathrm{Cl}$ & $\begin{array}{c}\text { Mean difference adjusted } \\
\text { for baseline }(95 \% \mathrm{Cl})\end{array}$ & P-value \\
\hline BMI-SDS & -0.4 & $-0.8 ; 0.0$ & -0.1 & $-0.4 ; 0.3$ & $-0.2(0.03 ; 0.42)$ & 0.02 \\
\hline WC-SDS & -0.6 & $-1.2 ;-0.0$ & -0.2 & $-0.7 ; 0.5$ & $-0.4(0.04 ; 0.78)$ & 0.03 \\
\hline $\mathrm{WC} / \mathrm{Ht}$ & -0.03 & $-0.06 ; 0.0$ & -0.01 & $-0.03 ; 0.0$ & $-0.02(0.001 ; 0.034)$ & 0.03 \\
\hline $\mathrm{VO}_{2 \text { peak }}-\mathrm{SDS}$ & 0.0 & $-0.7 ; 0.8$ & -1.1 & $-1.8 ;-0.4$ & $0.7(-1.1 ;-0.3)$ & $<0.01$ \\
\hline $\mathrm{VO}_{2 \text { peak }}-\mathrm{SDS}-\mathrm{kg}$ & 0.5 & $-0.0 ; 1.1$ & -0.4 & $-0.9 ; 0.1$ & $-0.7(-1.1 ;-0.4)$ & $<0.01$ \\
\hline Glucose $\left(\mathrm{mmoll}^{-1}\right)$ & -0.2 & $-0.3 ; 0.0$ & -0.0 & $(-0.3 ; 0.2)$ & $0.1(-0.1 ; 0.3)$ & NS \\
\hline Insulin $\left(\mathrm{mUI}^{-1}\right)$ & 1.0 & $-7.2 ; 5.2$ & 3.9 & $-1.1 ; 8.9$ & $-4.0(-0.0 ; 8.0)$ & 0.05 \\
\hline HOMA-SDS & 0.1 & $-1.1 ; 1.1$ & 0.6 & $-0.5 ; 1.6$ & $-0.9(0.0 ; 1.7)$ & 0.04 \\
\hline $\mathrm{HDL}\left(\mathrm{mmoll}{ }^{-1}\right)$ & -0.0 & $-0.2 ; 0.1$ & -0.0 & $-0.2 ; 0.1$ & $-0.03(-0.11 ; 0.06)$ & NS \\
\hline Triglycerides $\left(\mathrm{mmoll}^{-1}\right)$ & -0.1 & $-0.5 ; 0.4$ & 0.1 & $-0.2 ; 0.4$ & $-0.04(-0.3 ; 0.2)$ & NS \\
\hline $\mathrm{SBP}(\mathrm{mm} \mathrm{Hg})$ & -6.6 & $-12.2 ;-1.0$ & -4.3 & $-10.2 ; 1.7$ & $-2.8(-7.0 ; 1.5)$ & NS \\
\hline $\mathrm{DBP}(\mathrm{mm} \mathrm{Hg})$ & -7.3 & $-11.5 ;-3.1$ & -5.7 & $-10.0 ;-1.3$ & $-3.2(-6.7 ; 0.4)$ & NS \\
\hline Adiponectin ( $\mathrm{ng} \mathrm{ml}^{-1}$ ) & 0.8 & $-1.5 ; 3.0$ & 0.4 & $-1.4 ; 2.3$ & $0.2(-0.9 ; 1.4)$ & NS \\
\hline $\mathrm{hsCRP}\left(\mathrm{mg} \mathrm{I}^{-1}\right)$ & -0.4 & $-1.4 ; 0.6$ & -0.9 & $-3.2 ; 1.4$ & $-0.8(-1.6 ; 0.1)$ & NS \\
\hline
\end{tabular}

Abbreviations: BMI-SDS, body mass index-standard deviation score; $\mathrm{Cl}$, confidence interval; DBP, diastolic blood pressure; HDL, high-density lipoprotein; HOMASDS, standard deviation scores for Homeostasis Model Assessment for insulin resistance; hsCRP, high-sensitive C-reactive protein; NS, not significant; SBP, systolic blood pressure; $\mathrm{VO}_{2 \text { peak }}$-SDS-kg, absolute oxygen uptake by body weight ( $\mathrm{ml} \mathrm{min}^{-1}$ per $\mathrm{kg}$ ) and standardized it for age and gender; $\mathrm{VO}_{2 \text { peak }}$-SDS, absolute measured peak value of oxygen uptake $\left(\mathrm{ml} \mathrm{min}^{-1}\right)$, standardized for age and gender; WC/Ht; waist circumference and height ratio; WC-SDS, WC expressed as standard deviation score.

Table 5 Pearson correlation coefficients of the study parameters at baseline

\begin{tabular}{|c|c|c|c|c|c|c|c|c|c|c|c|c|c|c|}
\hline & $\begin{array}{l}\text { BMI- } \\
\text { SDS }\end{array}$ & $\begin{array}{l}W C- \\
S D S\end{array}$ & $\begin{array}{c}W C / \\
H t\end{array}$ & $\begin{array}{c}V_{2 \text { peak- }} \\
\text { SDS }\end{array}$ & $\begin{array}{c}V_{2 \text { peak- }} \\
\text { SDS-kg }\end{array}$ & $\begin{array}{l}\text { Fasting } \\
\text { glucose }\end{array}$ & $\begin{array}{l}\text { Fasting } \\
\text { insulin }\end{array}$ & $\begin{array}{c}\text { HOMA- } \\
\text { SDS }\end{array}$ & $H D L$ & $T G$ & $S B P$ & $D B P$ & Adiponetine & $h s C R P$ \\
\hline BMI-SDS & - & & & & & & & & & & & & & \\
\hline WC-SDS & $0.000^{* *}$ & - & & & & & & & & & & & & \\
\hline $\mathrm{WC} / \mathrm{Ht}$ & $0.000^{* *}$ & $0.962^{\star *}$ & - & & & & & & & & & & & \\
\hline $\mathrm{VO}_{2 \text { peak }}-\mathrm{SDS}$ & $0.000^{* *}$ & 0.620 ** & $0.487^{* *}$ & - & & & & & & & & & & \\
\hline $\mathrm{VO}_{2 \text { peak }}-\mathrm{SDS}-\mathrm{kg}$ & $0.000^{* *}$ & $-0.737^{* *}$ & $-0.755^{\star *}$ & -0.061 & - & & & & & & & & & \\
\hline Fasting glucose & 0.032 & 0.042 & 0.091 & -0.158 & $-0.050^{*}$ & - & & & & & & & & \\
\hline Fasting insulin & $0.000^{\star *}$ & $0.331^{* *}$ & $0.298^{*}$ & 0.040 & $-0.354^{\star *}$ & $0.304^{\star *}$ & - & & & & & & & \\
\hline HOMA-SDS & $0.189 * * *$ & $0.217^{*}$ & $0.239^{*}$ & -0.017 & $-0.356^{\star *}$ & $0.457^{* *}$ & $0.433^{* *}$ & - & & & & & & \\
\hline $\mathrm{HDL}$ & $0.000 * *$ & $-0.466^{\star \star}$ & $-0.429^{\star *}$ & $-0.326^{\star *}$ & 0.001 ** & -0.048 & $-0.223^{*}$ & $-0.243^{* *}$ & - & & & & & \\
\hline TG & $0.006^{\star *}$ & $0.282^{\star *}$ & $0.249^{* *}$ & 0.139 & $-0.021^{*}$ & 0.047 & $0.366^{\star *}$ & 0.125 & $-0.370^{* *}$ & - & & & & \\
\hline SBP & $0.001^{* *}$ & $0.398^{* *}$ & $0.379^{* *}$ & 0.173 & $0.000^{*}$ & 0.056 & 0.163 & $0.213^{*}$ & $-0.286^{* *}$ & $0.202^{*}$ & - & & & \\
\hline DBP & -0.916 & 0.054 & 0.058 & 0.012 & -0.855 & -0.008 & 0.049 & 0.079 & -0.097 & 0.114 & $0.269^{* *}$ & - & & \\
\hline Adiponectin & $-0.005^{\star *}$ & $-0.272^{\star *}$ & $-0.240^{\star}$ & -0.118 & $0.008^{* *}$ & -0.049 & $-0.391^{\star *}$ & $-0.297^{* *}$ & $0.323^{* *}$ & -0.110 & $-0.220^{\star}$ & 0.001 & - & \\
\hline hsCRP & $0.019^{*}$ & $-0.189^{*}$ & $0.242^{\star *}$ & 0.070 & $0.000^{* *}$ & 0.106 & -0.008 & -0.036 & $-0.197^{\star}$ & -0.056 & 0.043 & 0.109 & -0.089 & - \\
\hline
\end{tabular}

Abbreviations: BMI-SDS, body mass index-standard deviation score; $\mathrm{Cl}$, confidence interval; DBP, diastolic blood pressure; HDL, high-density lipoprotein; HOMASDS, standard deviation scores for Homeostasis Model Assessment for insulin resistance; hsCRP, high-sensitive C-reactive protein; SBP, systolic blood pressure;

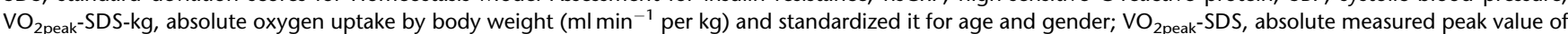
oxygen uptake $\left(\mathrm{ml} \mathrm{min}^{-1}\right)$, standardized for age and gender; TG, triglyceride; WC/Ht; waist circumference and height ratio; WC-SDS, WC expressed as standard deviation score. ${ }^{\star}$ Correlation is significant at 0.05 level (two-tailed); ${ }^{* *}$ correlation is significant at 0.01 level (two-tailed); ${ }^{* \star *}$ correation is $0.189(P=0.045)$.

control group. Results for parameters of lipid profile and inflammation showed no significant treatment effect.

The current recommendation for treating childhood obesity is a multidisciplinary lifestyle intervention with parental involvement. However, only few programs have been evaluated and the effect on retaining weight reduction over time is from small to moderate. ${ }^{14,16,35}$ These previous observations are confirmed by our study, showing a positive short- and long-term intervention effect on adiposity and physical fitness. Regarding the short-term treatment effect on adiposity, our results are similar to those of numerous previous studies on multidisciplinary lifestyle interventions in obese children. ${ }^{16,20,21,24}$ The follow-up results of such interventions are more diverse. Although, in agreement with our findings, some investigators observed still a reduced BMI-SDS after $\geqslant 1$-year follow-up; ${ }^{14,18}$ others reported less favorable follow-up results. ${ }^{14,21}$ Nevertheless, on average, the children were still obese during these follow-up measures. However, even if such interventions cannot reduce body weight to the normal range, beneficial results on health can be accomplished by improving physical fitness, nutritional habits and coping strategies. ${ }^{14,35}$ 
Waist circumference is used as a safe, easy and inexpensive way to measure abdominal obesity in adults and children, and is considered a good indicator of increased metabolic and cardiovascular risk. ${ }^{36}$ According to a previous study, obese children only had an increased metabolic and cardiovascular risk compared with normal-weight children if WC was >90th percentile for age and gender. ${ }^{36}$ In addition, among Asian-Indian adolescents, the odds of having hypertension was more pronounced for increased WC $(5.21$; 95\% confidence interval (2.14-12.17)) than for increased BMI (2.90; 95\% confidence interval (1.40-6.12)). ${ }^{37}$ These findings suggest that during treatment not only a reduction of BMI-SDS but also a lower WC is important to establish a beneficial health effect. In this light, our observations of a significant positive treatment effects on WC-SDS over time suggest being of greater importance for improvement of metabolic risk than the reduction of BMI-SDS.

The beneficial effect of multidisciplinary lifestyle interventions has been shown to increase when parents are in some way involved in the intervention. ${ }^{35}$ Hence, in order to achieve a larger treatment effect more emphasis should be put on motivating the parents to participate and support their child. The inclusion of the parents in the treatment of childhood obesity is challenging and health professionals are often confronted with the lack of parental motivation and with time constraints of the parents. A further obstacle in the struggle against childhood obesity is the unrealistic treatment expectations of children and parents. In most studies, including the current one, children who participate in a multidisciplinary lifestyle intervention do not lose all their excess body weight, which most families find difficult to accept. In order to match expectations with treatment objectives, it is advised to include an interview with the child and parents before the program. The purpose of this interview is to give the family a chance to reflect their willingness to participate, and discuss achievable realistic treatment goals. Although we included such an interview in our program, the child and parents kept focusing on the absolute amount of body weight loss and found it difficult to maintain the newly learned lifestyle. Therefore, the period immediately after the family-based multidisciplinary lifestyle intervention is critical for motivating children and their parents to maintain their changed lifestyle. In this respect, it may be important to emphasize the favorable effects of the achieved results in terms of body proportions and metabolic parameters, rather than the modest weight reduction obtained by the large majority.

Besides the treatment effect on adiposity, we also found a significant effect on physical fitness. Our data showed a significant improvement of fitness over time as opposed to a significant deterioration of physical fitness when BMI-SDS was unchanged as seen in the untreated controls. It has been suggested that the measured absolute peak $\mathrm{VO}_{2}$ in obese subjects may overestimate the real physical fitness because of their increased body size. ${ }^{30}$ For that reason, the peak $\mathrm{VO}_{2}$ adjusted for body weight, age and gender $\left(\mathrm{VO}_{2 \text { peak }}-\mathrm{SDS}-\mathrm{kg}\right)$ is often determined to establish a more realistic value for the physical fitness. In line with earlier studies, ${ }^{20,38}$ we found in our intervention group an unchanged absolute physical fitness $\left(\mathrm{VO}_{2 \text { peak }}-\mathrm{SDS}\right)$ over time, whereas physical fitness adjusted for body weight improved. It appears that absolute fitness is unaffected by treatment, but both measures for physical fitness diminished over time in our obese control group. A stable absolute physical fitness over time has been suggested to be indicative of training adaptation. ${ }^{38}$ As peak oxygen consumption is directly related to fat-free mass ${ }^{30}$ and subjects' fat mass, as well as their fat-free mass often decrease during weight reduction, their absolute physical fitness is expected to be lower at the end of treatment. An obstacle in maintaining prolonged weight reduction is, however, that during weight loss not only body weight decreases but, as a consequence of the reduced body weight, also the average daily energy requirements. For prolonged weight reduction, it will be beneficial to increase physical fitness in order to prevent the loss of fat-free mass during the weight-loss period. As we did not measure the fat-free mass in our study, we were unable to determine a possible positive-training adaption.

The intervention did not improve insulin resistance, but still a treatment effect was observed because of the increased insulin resistance in the control group. In contrast to our results, previous studies have found a significantly decreased HOMA-IR and fasting insulin after a lifestyle intervention. These decreased markers for insulin resistance were found when clinically significant weight reduction (>0.5 BMI-SDS) occurred, ${ }^{22}$ or when BMI and body weight were significantly reduced. ${ }^{19}$ It should, however, be noted that the result of the latter study was found in only 48 of the 104 children (47.5\%) after completion of the intervention. Therefore, it is conceivable that, in this study, markers for insulin resistance were determined only in the children with weight reduction.

The results of the present study confirm the previously reported association between childhood obesity and the presence of a pro-inflammatory state, indicated by a significantly increased hsCRP serum concentration. ${ }^{7-9}$ On the contrary, adiponectin exerts an anti-atherogenic effect and has previously been found in lower concentrations in obese compared with normal-weight children. ${ }^{10,19,22}$ Adiponectin is also reported to improve insulin sensitivity. ${ }^{39}$ In contrast to these earlier studies, we found similar adiponectin concentrations in the obese and lean children. A beneficial effect of our family-based multidisciplinary lifestyle intervention on the inflammatory state was absent. In earlier studies, a clinically significant BMI-SDS reduction of $>0.5$ has been ${ }^{9,22}$ associated with a significant increase in adiponectin and decrease in hsCRP. We speculate that the modest BMI-SDS reduction after intervention may explain the absence of a treatment effect on both.

One of the limitations of this study is that our study population consisted of a clinically referred sample and thereby may be influenced by selection and referral bias, and 
thus may not be representative for all (severely) obese children in the general population. Treatment-seeking children with obesity probably experience more disadvantages from their excess body weight and are therefore perhaps more motivated than their obese peers in the community. Another limitation of the current study is that for the follow-up at 2 years, no obese control data were available, as, for ethical reasons, the obese control group was offered the same intervention at 1-year follow-up. Finally, it is unknown what the predictive value is of 2-year follow-up data for health and behavior in later years.

The strength of this study is the prospective, randomized and controlled study design, with sufficient statistical power, and the breadth of outcome parameters, including physical fitness. Since at all points in time, during our study, measurements were taken by the same person under similar conditions, the results cannot be biased by inter-observer errors.

In conclusion, our intensive family-based multidisciplinary lifestyle intervention resulted in a modest long-term reduction of both total and abdominal adiposity accompanied by improved physical fitness, whereas unchanged adiposity in untreated controls led to decreased physical fitness and deterioration of insulin resistance state. No effect was seen on inflammatory markers, probably because almost all children remained obese.

\section{Conflict of interest}

The study was partly funded by an unrestricted educational grant by Pfizer and an unrestricted educational grant by a non-profit foundation (de Stichting Vrienden van het JKZ). The sponsors had no role in the study design, data collection and analysis or in the content of the manuscript. The corresponding author has full access to all data in the study. All authors declare no conflict of interest. This research was carried out at the Department of Pediatrics, Juliana Children's Hospital, The Hague, The Netherlands.

\section{Acknowledgements}

We thank all members of the multidisciplinary team, for their time and patience in treating the children, and we thank the participating children and their families in this study. We thank the members of the short-stay unit and the Department of Lung Diseases for their assistance during the measurements of physical fitness. In addition, we thank the staff of the Clinical Chemical Laboratory, Juliana Children's Hospital, The Hague, The Netherlands and members of the Clinical Chemical Laboratory, Leiden University Medical Centre, Leiden, The Netherlands, for their assistance in analyzing the blood samples.

Trial Registration: http://www.controlled-trials.com/ISRCTN 36146436.

\section{References}

1 Popkin BM, Gordon-Larsen P. The nutrition transition: worldwide obesity dynamics and their determinants. Int $J$ Obes Relat Metab Disord 2004; 28(Suppl 3): S2-S9.

2 Guo SS, Wu W, Chumlea WC, Roche AF. Predicting overweight and obesity in adulthood from body mass index values in childhood and adolescence. Am J Clin Nutr 2002; 76: 653-658.

3 Mossberg HO. 40-year follow-up of overweight children. Lancet 1989; 2: 491-493.

4 Must A, Jacques PF, Dallal GE, Bajema CJ, Dietz WH. Long-term morbidity and mortality of overweight adolescents. A follow-up of the Harvard Growth Study of 1922-1935. N Engl J Med 1992; 327: 1350-1355.

5 Sbarbati A, Osculati F, Silvagni D, Benati D, Galie M, Camoglio FS et al. Obesity and inflammation: evidence for an elementary lesion. Pediatrics 2006; 117: 220-223.

6 Stefanyk LE, Dyck DJ. The interaction between adipokines, diet and exercise on muscle insulin sensitivity. Curr Opin Clin Nutr Metab Care 2010; 13: 255-259.

7 Alvarez JA, Higgins PB, Oster RA, Fernandez JR, Darnell BE, Gower BA. Fasting and postprandial markers of inflammation in lean and overweight children. Am J Clin Nutr 2009; 89: 1138-1144.

8 Balagopal P, George D, Patton N, Yarandi H, Roberts WL, Bayne E et al. Lifestyle-only intervention attenuates the inflammatory state associated with obesity: a randomized controlled study in adolescents. J Pediatr 2005; 146: 342-348.

9 Reinehr T, Stoffel-Wagner B, Roth CL, Andler W. High-sensitive C-reactive protein, tumor necrosis factor alpha, and cardiovascular risk factors before and after weight loss in obese children. Metabolism 2005; 54: 1155-1161.

10 Balagopal P, George D, Yarandi H, Funanage V, Bayne E. Reversal of obesity-related hypoadiponectinemia by lifestyle intervention: a controlled, randomized study in obese adolescents. J Clin Endocrinol Metab 2005; 90: 6192-6197.

11 Halle M, Korsten-Reck U, Wolfarth B, Berg A. Low-grade systemic inflammation in overweight children: impact of physical fitness. Exerc Immunol Rev 2004; 10: 66-74.

12 Ebbeling CB, Pawlak DB, Ludwig DS. Childhood obesity: publichealth crisis, common sense cure. Lancet 2002; 360: 473-482.

13 Kitzmann KM, Dalton III WT, Stanley CM, Beech BM, Reeves TP, Buscemi $\mathrm{J}$ et al. Lifestyle interventions for youth who are overweight: a meta-analytic review. Health Psychol 2010; 29: 91-101.

14 Oude LH, Baur L, Jansen H, Shrewsbury VA, O'Malley C, Stolk RP et al. Interventions for treating obesity in children. Cochrane Database Syst Rev 2009; (1): CD001872.

15 Taveras EM, Mitchell K, Gortmaker SL. Parental confidence in making overweight-related behavior changes. Pediatrics 2009; 124: 151-158.

16 Singhal N, Misra A, Shah P, Gulati S. Effects of controlled schoolbased multi-component model of nutrition and lifestyle interventions on behavior modification, anthropometry and metabolic risk profile of urban Asian Indian adolescents in North India. Eur J Clin Nutr 2010; 64: 364-373.

17 Braet C, Van WM, Van LK. Follow-up results of different treatment programs for obese children. Acta Paediatr 1997; 86: 397-402.

18 Reinehr T, Widhalm K, l'Allemand D, Wiegand S, Wabitsch M, Holl RW. Two-year follow-up in 21784 overweight children and adolescents with lifestyle intervention. Obesity (Silver Spring) 2009; 17: 1196-1199.

19 Cambuli VM, Musiu MC, Incani M, Paderi M, Serpe R, Marras V et al. Assessment of adiponectin and leptin as biomarkers of positive metabolic outcomes after lifestyle intervention in overweight and obese children. J Clin Endocrinol Metab 2008; 93: 3051-3057.

20 Kirk S, Zeller M, Claytor R, Santangelo M, Khoury PR, Daniels SR. The relationship of health outcomes to improvement in BMI in children and adolescents. Obes Res 2005; 13: 876-882. 
21 Lazzer S, Vermorel M, Montaurier C, Meyer M, Boirie Y. Changes in adipocyte hormones and lipid oxidation associated with weight loss and regain in severely obese adolescents. Int J Obes (Lond) 2005; 29: 1184-1191.

22 Reinehr T, Roth C, Menke T, Andler W. Adiponectin before and after weight loss in obese children. J Clin Endocrinol Metab 2004; 89: 3790-3794.

23 Reinehr T, Kleber M, Toschke AM. Lifestyle intervention in obese children is associated with a decrease of the metabolic syndrome prevalence. Atherosclerosis 2009; 207: 174-180.

24 Weigel C, Kokocinski K, Lederer P, Dotsch J, Rascher W, Knerr I. Childhood obesity: concept, feasibility, and interim results of a local group-based, long-term treatment program. I Nutr Educ Behav 2008; 40: 369-373.

25 Reinehr T, Kleber M, Lass N, Toschke AM. Body mass index patterns over 5 years in obese children motivated to participate in a 1-y lifestyle intervention: age as a predictor of long-term success. Am J Clin Nutr 2010; 91: 1165-1171.

26 Cole TJ, Bellizzi MC, Flegal KM, Dietz WH. Establishing a standard definition for child overweight and obesity worldwide: international survey. BMJ 2000; 320: 1240-1243.

27 Cole TJ, Roede MJ. Centiles of body mass index for Dutch children aged 0-20 years in 1980 - a baseline to assess recent trends in obesity. Ann Hum Biol 1999; 26: 303-308.

28 Fredriks AM, Van Buuren S, Fekkes M, Verloove-Vanhorick SP, Wit JM. Are age references for waist circumference, hip circumference and waist-hip ratio in Dutch children useful in clinical practice? Eur I Pediatr 2005; 164: 216-222.

29 Tanner J. Growth at Adolescence: with a General Consideration of the Effects of Hereditary and Enviromental Factors Upon Growth and Maturation from Birth to Maturity, 2nd edn. Blackwell Scientific Publications: Oxford, 1962.

30 Wasserman K, Hansen JE, Sue DY, Stringer WW, Whipp BJ. Principles of Exercise Testing and Interpretation, 4th edn. Lippincott Williams \& Wilkins: Philadelphia, PA, USA, 2005.

31 Borg G. Psychophysical scaling with applications in physical work and the perception of exertion. Scand J Work Environ Health 1990; 16(Suppl 1): 55-58.
32 Takken T. Inspanningstests. Elsevier gezondheidszorg: Maarssen, 2004.

33 Matthews DR, Hosker JP, Rudenski AS, Naylor BA, Treacher DF, Turner RC. Homeostasis model assessment: insulin resistance and beta-cell function from fasting plasma glucose and insulin concentrations in man. Diabetologia 1985; 28: 412-419.

34 Allard P, Delvin EE, Paradis G, Hanley JA, O'Loughlin J, Lavallee $\mathrm{C}$ et al. Distribution of fasting plasma insulin, free fatty acids, and glucose concentrations and of homeostasis model assessment of insulin resistance in a representative sample of Quebec children and adolescents. Clin Chem 2003; 49: 644-649.

35 McGovern L, Johnson JN, Paulo R, Hettinger A, Singhal V, Kamath $\mathrm{C}$ et al. Clinical review: treatment of pediatric obesity: a systematic review and meta-analysis of randomized trials. J Clin Endocrinol Metab 2008; 93: 4600-4605.

36 Maffeis C, Banzato C, Talamini G. Waist-to-height ratio, a useful index to identify high metabolic risk in overweight children. I Pediatr 2008; 152: 207-213.

37 Goel R, Misra A, Agarwal SK, Vikram N. Correlates of hypertension among urban Asian Indian adolescents. Arch Dis Child 2010; 95: 992-997.

38 Deforche B, De Bourdeaudhuij I, Debode P, Vinaimont F, Hills AP, Verstraete $\mathrm{S}$ et al. Changes in fat mass, fat-free mass and aerobic fitness in severely obese children and adolescents following a residential treatment programme. Eur J Pediatr 2003; 162: 616-622.

39 Jeffery AN, Murphy MJ, Metcalf BS, Hosking J, Voss LD, English P et al. Adiponectin in childhood. Int J Pediatr Obes 2008; 3: 130-140.

40 Epstein LH, Wing RR, Valoski A. Childhood obesity. Pediatr Clin North Am 1985; 32: 363-379.

This work is licensed under the Creative Commons Attribution-NonCommercial-No Derivative Works 3.0 Unported License. To view a copy of this license, visit http://creativecommons.org/ licenses/by-nc-nd/3.0/ 